\title{
Risk factors for antimicrobial use in veal calves and the association with mortality
}

\author{
J. Bokma, ${ }^{1 *}$ R. Boone, ${ }^{2}$ P. Deprez, ${ }^{1}$ and B. Pardon ${ }^{1}$ \\ ${ }^{1}$ Department of Large Animal Internal Medicine, Faculty of Veterinary Medicine, Ghent University, Salisburylaan 133, 9820 Merelbeke, Belgium \\ ${ }^{2}$ Veterinary Practice Venhei, Geelsebaan 95-97, 2460 Kasterlee, Belgium
}

\begin{abstract}
The intensive use of antimicrobials in the veal industry is heavily criticized, but drivers for antimicrobial usage (AMU) are still poorly understood. The industry fears that a drastic reduction in AMU would increase mortality, creating an unacceptable welfare issue. The objectives of the present study were to identify risk factors for AMU and to explore the relationship between AMU and mortality. A retrospective cohort study was performed on the antimicrobial registration data from the largest Belgian veterinary veal practice. The data set contained 295 production cycles from 78 farms, representing 146,014 calves and 8 veal companies (also called integrations). The average AMU was 32.3 defined daily dose animal per year (standard deviation: 11.04), of which $76.2 \%$ was administered orally and $23.8 \%$ parentally. The AMU remained stable between 2014 and 2016 with only a slight, but significant increase in total AMU between 2015 (31.0 defined daily dose animal per year, standard deviation: 10.5) and 2016 (35.1, 10.8). Use of almost all antimicrobial classes decreased over 2014 to 2016; however, use of long-acting macrolides, doxycycline, and aminosides increased significantly. Analysis identified breed (higher use in beef calves compared with dairy and crossbreeds), month of arrival (lower use when arrived in April or May compared with winter months), and veal company as risk factors. The veal company not only significantly affected total AMU, but also affected the majority of the antimicrobial classes. Additionally, breed differences were present for oxytetracycline, colistin, and classic macrolides, and a month effect was present for doxycycline only. These data illustrate that this veterinary practice realized a reduction of $46 \%$ in total AMU and of $96 \%$ in critically important antibiotics (fluoroquinolones, cephalosporins of the third and fourth generation) compared with the Belgian benchmark from 2007 to 2009. Replacement of
\end{abstract}

Received June 14, 2018.

Accepted September 20, 2018.

*Corresponding author: jade.bokma@ugent.be critically important drugs by an increased use of longacting macrolides is worrisome. Mortality risk was very low compared with benchmarks referenced internationally and did not increase with decreasing AMU. Use of trimethoprim-sulfonamides was a risk factor, whereas use of oxytetracycline was a protective factor for mortality. The absence of a relationship with mortality at the current levels of AMU suggests that a further rational reduction is possible. Attention should be paid to consider different AMU benchmarks for different breeds and to include the veal company as a target for antibiotic awareness campaigns.

Key words: benchmark, breed, integration, welfare

\section{INTRODUCTION}

The veal calf sector is specialized in fattening predominantly male dairy calves from an age of 1 to 4 wk on, on different diets, varying from all-liquid (white veal) to high amounts of roughage (rosé veal) (Pardon et al., 2014). Worldwide, this industry is important to the dairy sector as it increases revenue from male calves and is an important regulator of different dairy products. Crossbreeding strategies are popular in the dairy industry to increase the value of the male calf, and separate veal segments specialized in crossbreeds and beef calves have developed. The current veal production systems inherently holds major risk factors for disease given the high degree of commingling and the required transport. Antimicrobial use (AMU) has always been essential to control diseases under such conditions (Pardon et al., 2012a; Lava et al., 2016a), but today the highly intensive AMU and associated high levels of antimicrobial resistance (AMR) in commensals and pathogens in the veal industry are heavily criticized (EMA/EFSA, 2016). No recent data on AMU in Belgian veal calves are available, but data from 2007 to 2009 showed that AMU in Belgian veal calves was very high (60 defined daily dose animal per year, DDDvet/ yr; Pardon et al., 2012a).

A reduction in AMU is urgently needed and several countries initiated laws and guidelines to achieve this. Benchmarking of AMU in all farms appears to be es- 
sential and different countries have set targets for reduction. For example, in the Netherlands a reduction of $70 \%$ in food-producing animals in 2020 compared with 2009 was aimed at Kamerbrief (2016), whereas in Belgium a reduction in total AMU of $50 \%$ and in the use of critically important antimicrobials (fluoroquinolones and third- and fourth-generation cephalosporins in this context) by $75 \%$ by 2020 is the target (AMCRA, 2016). Available studies on AMU in different species all demonstrate the large variation in usage, with farms hardly using any antimicrobials and others very intensively (Timmerman et al., 2006; Pardon et al., 2012a; Agunos et al., 2017). In other words, there appears to be a major window of opportunity to reduce usage, but the factors driving AMU in the veal industry are poorly understood (Fertner et al., 2016; Lava et al., 2016b; Jarrige et al., 2017). Knowledge on these drivers is essential to design effective campaigns and intervention measures to rationalize AMU in the short term and for the development of sustainable veal production systems in the future. A major concern of veal farmers and their veterinarians is that a reduction that is either too rapid or drastic would increase mortality. No longer treating sick animals or reducing required treatment length would seriously hamper animal welfare, eventually showing as an increased mortality as tip of the iceberg (Bengtsson and Greko, 2014). Despite several positive changes in housing and feeding, welfare concerns on veal production are persistent in the public opinion, and obviously higher mortality rates would not be tolerated (Pardon et al., 2014).

Therefore the objectives of our study were (1) to quantify AMU over 2014-2016 in white veal calves under guidance of a single veterinary practice in Belgium, (2) to identify risk factors associated with total AMU and the different antimicrobial classes separately, and (3) to explore the relationship between AMU and mortality. The working hypothesis was that a reduction of AMU would increase mortality.

\section{MATERIALS AND METHODS}

\section{Study Population and Data Collection}

Antimicrobial consumption data from one veterinary practice situated in Flanders (Belgium) was available. A retrospective cohort study was performed. All farms guided by this veterinary practice were eligible. Primary inclusion criteria were fattening veal calves, participation in the automatic AMU registration of this veterinary practice, and at least one completed production cycle in 1 of the 3 study years (2014-2016).

All data were collected from the software program manufactured by the veterinary practice, and exported to a spreadsheet (Excel, Microsoft 2016, Redmond, WA). Study size was determined by the availability of data. The preliminary data consisted of 83 farms, 342 production cycles, and 167,629 calves belonging to 12 independent veal companies (also called integrations). A veal company owns all domains of the production chain by having its own feed plant, transport, farms, and slaughterhouse. Data were screened for abnormalities and primary exclusion criteria were negative values, incomplete registration, and computer flaws. All calves were fattened on slatted floors in large compartments with natural or mechanical ventilation. The diet consisted of milk replacer and provision of iron and roughage at the minimal requirements as mentioned by European legislation (EC Directives 91/629/EEC and 97/2/EC).

\section{Antimicrobial Use Data}

Antimicrobials were assigned to different categories: fluoroquinolones (FluoroQ: danofloxacin, enrofloxacin, flumequine, and marbofloxacin), third and fourth generation cephalosporins (CS3/4: ceftiofur and cefquinome), classic macrolides (MacroC: tilmicosin, tylosin), long-acting macrolides (MacroLA: gamithromycin, tildipirosin, tulathromycin), colistin (COL), amoxicillin (AMX), doxycycline (DOX), oxytetracycline (OTC), aminosides (AminoS: gentamicin and neomycin), florphenicol (FLOR), trimethoprimsulphonamides (TMS), lincosamides (LincosA: lincomycin and spectinomycin), and penicillin [PEN: benzylpenicillin (+ neomycin) and fenoxymethylpenicillin]. Antimicrobial administration route was divided in mainly oral (AMX, DOX, MacroC, OTC, AminoS, COL, and TMS) and mainly parenteral (MacroLA, FluoroQ, FLOR, LincosA, CS3/4, and PEN) treatments.

Standard daily dose methodology was used to quantify AMU (Pardon et al., 2012a). The data collection system of the program was written to be in compliance with the Dutch national monitoring system and used the Dutch list of defined daily dosages (SDA, 2017). The AMU was calculated according to the next formula and expressed as a treatment incidence [defined daily dose animal per year (DDDvet/yr)]:

$$
\begin{gathered}
\text { Treatment incidence }(\text { DDDvet } / \mathrm{yr})= \\
\frac{\text { Total amount of antimicrobials used }(\mathrm{mg})}{\text { DDDvet }(\mathrm{mg} / \mathrm{kg}) \times \text { days at risk } \times \mathrm{BW}(\mathrm{kg})} \times 365 \mathrm{~d} \text {. }
\end{gathered}
$$

The numerator consists of the total amount of antimicrobials used in $\mathrm{mg}$ and the indicator is based on the defined daily dose for animals (EMA/710019/2014), 
the length of the production cycle (days at risk) and BW of the calf in kilograms. For quantification of total AMU, a standard BW of $160 \mathrm{~kg}$ (SW) was used to be able to compare AMU between countries and previous studies (Pardon et al., 2012a; Lava et al., 2016b). At the individual antimicrobial level, the program delivered the data expressed on an actual live weight $(\mathbf{L W})$ basis. This LW was estimated at the day of treatment initiation based on growth curves from the sector adjusted for breed. Given that an average of $160 \mathrm{~kg}$ is an overestimation of LW at the average treatment age (3-4 wk), using this SW underestimates AMU (Pardon et al., 2012a). Use of the LW offers a more realistic estimate of AMU. For long-acting preparations, DDDvet was divided by the corresponding long-acting factor in days, which was 24 for tildipirosin and 3 for tilmicosin and tulathromycin. After this calculation, the outcome was multiplied by $365 \mathrm{~d}$ to determine treatment incidence per year.

\section{Mortality Data}

Mortality data were also available in the software program, expressed as a mortality risk (number of dead calves/number of calves at arrival $\times 100)$. All cattle were identified with official ear tags and included in the national cattle registration databank (SANITRACE, Animal Health Service Flanders). As part of the SANITRACE system, the death of individual calves is confirmed at the point of disposal of the carcass.

\section{Statistical Analysis}

All data were transferred to SAS 9.4 (SAS Institute Inc., Cary, NC) for statistical analysis. The elementary unit of interest was the production cycle. Outcome variables (total AMU, specific AMU for FluoroQ, CS3/4, MacroC, MacroLA, COL, AMX, DOX, OTC, AminoS, FLOR, TMS, and LincosA) were checked for a normal distribution. Total AMU, AMX, DOX, and MacroC were normally distributed and analyzed as such. The FluoroQ reached a normal distribution after $\log (\mathrm{x}+1)$ transformation. The other outcomes (CS3/4, MacroLA, COL, OTC, AminoS, TMS, FLOR, and Lin$\cos \mathrm{A}$ ) showed a zero-inflated distribution. It was opted to create binary variables, representing no usage of the respective molecule (0) or usage (1).

Model Building Procedure for Continuous Outcomes. To determine the association of the 6 risk factors [breed (dairy, crossbreed, beef), month of arrival (January to December), year (2014, 2015, 2016), number of calves introduced, veal company, and mortality risk (\%)] with total AMU, AMX, DOX, MacroC, and FluoroQ, 5 separate linear mixed models (PROC
MIXED) were made. In each model, herd was added as a random effect to account for clustering of production cycles within a herd. Continuous predictors were tested as such and categorically in quartiles. The 3 largest veal companies were included in all analysis, but the smaller ones were combined if little usage of a certain antimicrobial class required grouping. All parameters with $P$ $<0.20$ were withheld for the next step. Pearson's and Spearman correlation were determined, and of predictors correlated over 0.6 , only the most significant one $(P$ $<0.05$ ) was withheld for the multivariable model. Each multivariable model was developed using a backward stepwise approach, gradually excluding nonsignificant variables. Pairwise comparisons between different categories of significant effects were made using Bonferonni corrections. Biologically plausible interactions between significant main effects were tested. Model fit was assessed by visual inspection of plots and normality testing of residuals. In all models significance was set at $P<0.05$ and $0.05 \leq P<0.10$ was considered a trend.

A multivariable linear regression model (PROC MIXED) was made to determine the association of the 5 predictors (year, month, herd size, breed, and veal company), total AMU, and the usage of all 12 antimicrobial classes with mortality. First univariable testing was done as described above and a backward stepwise method was used for the multivariable model building process. Herd was added as a random factor and all other settings were identical as described for the antimicrobial outcomes mentioned above.

Model Building Procedure for Binary Outcomes. To determine the association of the 5 risk factors with binary outcome variables (CS3/4, MacroLA, COL, OTC, AminoS, TMS, FLOR, and LincosA), a generalized linear mixed model (PROC GLIMMIX) was used with binomial distribution and logit link function with Wald's statistics for type 3 contrasts. Herd was added as a random factor to account for clustering. First, the same predictors as mentioned above were univariable tested. The same selection and significance criteria as mentioned above were used for the further model building procedure. Model fit was evaluated using the Hosmer-Lemeshow goodness-of-fit test for logistic models.

\section{RESULTS}

\section{Production Cycles}

Of the production cycles, $13.7 \%(47 / 342)$ were excluded because they exclusively fattened rosé calves (31 cycles) or due to registration mistakes (16). The final data set consisted of 295 production cycles from 78 white veal farms, belonging to 8 veal companies. More 
Table 1. Descriptive data of 78 veal farms, 295 production cycles, managed by a single veterinary practice in Flanders, Belgium $(2014-2016)^{1}$

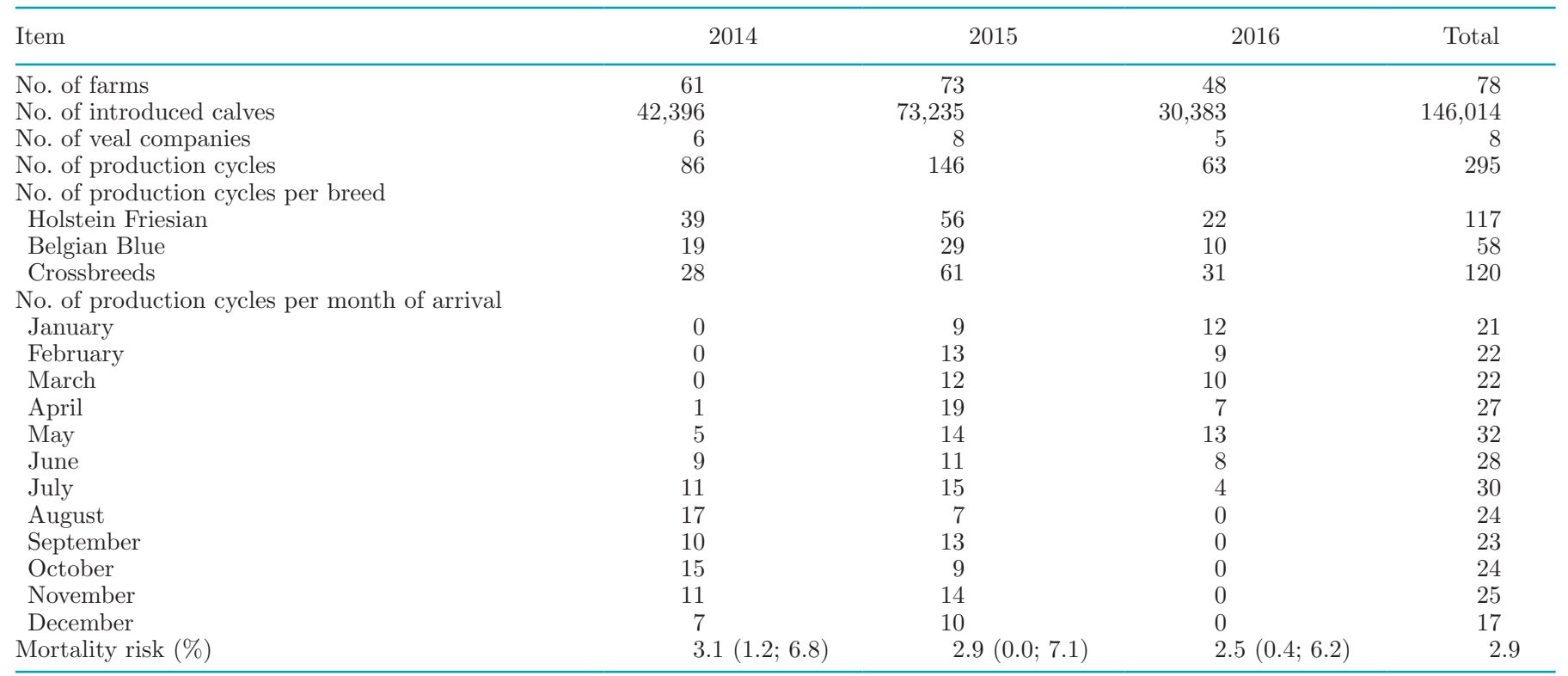

${ }^{1}$ Values are presented as described or in number of production cycles and minimum and maximum interval.

production cycles from 2014 to 2015 than from 2016 could be included, because not all production cycles initiated in 2016 were terminated when data were collected in January 2017 (Table 1). All animals in a production cycle belonged to the same breed (dairy, crossbreeds, or beef). Of the production cycles, $40 \%(117 / 295)$ of the cycles consisted of Holstein Friesians (HF), 20\% $(58 / 295)$ of Belgian Blues (BB), and 40\% (120/295) were crossbreeds $(\mathbf{H F} \times \mathbf{B B})$. In total 146,014 calves were fattened, of which $48.3 \%$ were $\mathrm{HF}, 15.3 \%$ were $\mathrm{BB}$, and $37.5 \%$ were $\mathrm{HF} \times \mathrm{BB}$. Mean herd size was 495 calves [SD: 216; range (R): 192-1,185] and this did not significantly differ between breeds. Production cycles started most frequent in May (11\%) and least frequent in December (6\%; Table 1).

\section{Total Antimicrobial Use and Associated Risk Factors}

Based on a SW of $160 \mathrm{~kg}$, average total AMU was 32.3 DDDvet/yr (SW; SD: 11.04; R: 9.2-60.5) and 76.2 and $23.8 \%$ was administered orally and parenterally, respectively (Table 2). The AMU was highly variable at the farm level ranging from 10.3 to 55.7 DDDvet/yr (SW; Figure 1). A trend $(P=0.07)$ was observed toward a positive association between parenteral and oral use. When plotting oral and parenteral AMU, 2 distinct populations could be seen (Figure 2). The explanatory factor for these different populations was the use of MacroLA, which is associated with parenteral use.

In 2014, 2015, and 2016, an average of, respectively, 32.5 (SD: 11.8; R: 10.7-55.9), 31.0 (SD: 10.5; R: 9.257.80), and 35.1 (SD: 10.8; R: 11.1-60.5) DDDvet/yr
(SW) was used. Also averages between breeds differed significantly: $\mathrm{BB}$ (37.2; SD: 10.6; R: 15.1-60.5), HF (26.4; SD: 10.6; R: 9.2-55.7), and $\mathrm{HF} \times \mathrm{BB}$ (35.7; SD: 8.9; R: 14.0-56.8). Based on real LW, total AMU was markedly higher, namely on average 85.0 DDDvet/yr (SD: 29.0; R: 17.4-159.4) and 29.7\% was given parenterally and $70.3 \%$ orally.

Univariable analysis for total AMU based on SW showed year, breed, veal company, month of arrival, and number of calves (per 100) as risk factors. In the final multivariable model, year, breed, veal company, and month of arrival remained significant (Table 3). Total AMU was higher in winter months compared with April and May as shown in Figure 3.

\section{Usage of Critically Important Antimicrobials and Associated Risk Factors}

Usage per antimicrobial class and trends over the study years are provided in Table 2 and Figure 4, respectively. The FluoroQ were markedly more used than CS3/4, but COL was used the most, given its oral application (6.8 DDDvet/yr). FluoroQ $(P<0.05)$, CS3/4 $(P<0.05)$, and COL $(P<0.001)$ all decreased significantly between 2014 and 2016. The FluoroQ were used in almost all production cycles, and COL and MacroLA were used on the majority of farms (Figure 5). The use of CS3/4 was much less frequent and decreased over the years. In contrast, the percentage of farms using MacroLA increased in 2016. A summary of outcomes of the multivariable linear models for the different critically important antimicrobials is shown in Table 4. Year was 


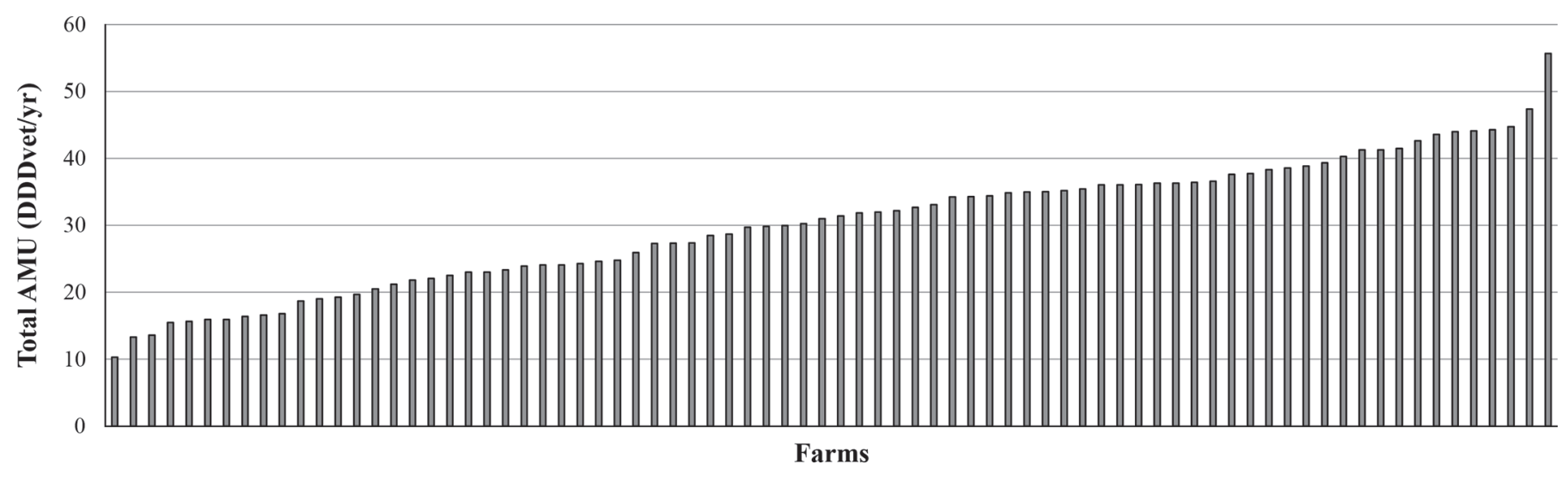

Figure 1. Distribution of total antimicrobial use [defined daily dose animal per year (DDDvet/yr), standard weight] of 78 veal farms, 295 production cycles, managed by a single veterinary practice in Flanders, Belgium (2014-2016).

a risk factor for all critically important classes (FluoroQ: $2014>2015,2016 ;$ CS3/4: $2014>2016$; COL: 2014, $2015>2016$; MacroLA: $2015<2016$ ), as was veal company (FluoroQ: $4>1-3,6-8$, and $2>1,3,8$; CS3/4: clustered veal company; COL: $1<3$; MacroLA: $0,1>4)$. With regard to breed, only a trend in the use of $\mathrm{COL}(\mathrm{HF}>\mathrm{BB}, \mathrm{HF} \times \mathrm{BB})$ was noted.

\section{Usage of Other Antimicrobial Classes and Associated Risk Factors}

Usage per antimicrobial class and trends over the study years are provided in Table 2 and Figure 4, re- spectively. Overall, MacroLA were used the most and use of PEN was almost non-existent. Administration of OTC $(P<0.05)$, MacroC $(P<0.05)$, TMS $(P<$ $0.001)$, LincosA $(P<0.05)$, and PEN $(P<0.05)$ decreased over 2014-2016. Significant increase in usage of MacroLA $(P<0.001)$, DOX $(P<0.05)$ and AminoS $(P<0.001)$ was seen. For the remaining antimicrobial classes, year, month of arrival, breed, veal company and herd size (per 100 calves) were risk factors (Table 4). Only for DOX an effect of the month of arrival was noted with a higher usage in July and August compared with January, February, March, and May. Also in August, more consumption was seen than in January,

Table 2. Descriptive statistics concerning quantitative antimicrobial use (AMU) over 78 veal farms, 295 production cycles, managed by a single veterinary practice in Flanders, Belgium $(2014-2016)^{1}$

\begin{tabular}{|c|c|c|c|c|c|}
\hline Item & Mean & $\mathrm{SD}$ & Minimum & Maximum & $\begin{array}{l}\text { Percentage of } \\
\text { total AMU }\end{array}$ \\
\hline Total $\mathrm{AMU}_{\mathrm{SW}}$ & 32.3 & 11.0 & 9.2 & 60.5 & \\
\hline Orally & 24.6 & 8.2 & 6.3 & 51.1 & 76.2 \\
\hline Parenterally & 7.7 & 5.9 & 0.0 & 23.7 & 23.8 \\
\hline Total $\mathrm{AMU}_{\mathrm{LW}}$ & 85.0 & 29.0 & 17.4 & 159.4 & \\
\hline Orally & 59.8 & 17.1 & 12.3 & 115.2 & 70.3 \\
\hline Parenterally & 25.2 & 19.9 & 0 & 78.1 & 29.7 \\
\hline \multicolumn{6}{|l|}{ Antimicrobial classes (SW) } \\
\hline \multicolumn{6}{|l|}{ Mainly orally administered } \\
\hline Amoxicilline & 20.6 & 12.5 & 0 & 85.5 & 24.8 \\
\hline Doxycycline & 10.8 & 6.1 & 0 & 32.1 & 13.0 \\
\hline Macrolides classic & 9.4 & 6.1 & 0 & 37.0 & 11.3 \\
\hline Oxytetracycline & 6.3 & 6.6 & 0 & 30.5 & 7.5 \\
\hline Aminosides & 5.2 & 5.3 & 0 & 19.7 & 6.2 \\
\hline Colistin & 5.1 & 6.8 & 0 & 25.0 & 6.1 \\
\hline Trimethoprim-sulfonamides & 0.2 & 1.1 & 0 & 11.7 & 0.3 \\
\hline \multicolumn{6}{|l|}{ Mainly parenterally administered } \\
\hline Long-acting macrolides & 23.4 & 20.5 & 0 & 77.1 & 28.2 \\
\hline Fluoroquinolones & 1.6 & 1.4 & 0 & 11.7 & 1.9 \\
\hline Florphenicol & 0.3 & 0.4 & 0 & 3.2 & 0.4 \\
\hline Lincosamides & 0.1 & 0.2 & 0 & 1.5 & 0.2 \\
\hline Cephalosporins (3rd/4th) & 0.1 & 0.2 & 0 & 1.2 & 0.1 \\
\hline Penicillin & 0.01 & 0.1 & 0 & 1.1 & 0.01 \\
\hline
\end{tabular}

${ }^{1} \mathrm{AMU}$ is expressed in veterinary daily dose per year (DDDvet/yr) based on standard weight (SW) and live weight (LW). 
Table 3. Results of the multivariable linear model for factors associated with total antimicrobial use (defined daily dose animal, standard weight) in veal calves over 78 veal farms, 295 production cycles, managed by a single veterinary practice in Flanders, Belgium (2014-2016)

\begin{tabular}{|c|c|c|c|c|}
\hline Parameter & Category & $\beta$ & $95 \%$ CI & $P$-value \\
\hline Intercept & & 32.6 & 26.0 to 39.2 & $<0.0001$ \\
\hline \multirow[t]{3}{*}{ Year } & 2016 & Referent & & $<0.001$ \\
\hline & 2014 & -3.7 & -6.9 to -0.6 & 0.06 \\
\hline & 2015 & -4.8 & -7.2 to -2.3 & $<0.001$ \\
\hline \multirow[t]{3}{*}{ Breed $^{1}$} & $\mathrm{BB}$ & Referent & & 0.02 \\
\hline & $\mathrm{HF}$ & -4.4 & -8.0 to -0.8 & 0.05 \\
\hline & $\mathrm{HF} \times \mathrm{BB}$ & -4.3 & -7.4 to -1.1 & 0.02 \\
\hline \multirow[t]{8}{*}{ Veal company } & 1 & Referent & & $<0.001$ \\
\hline & 2 & 4.8 & 0.2 to 9.4 & $<0.001$ \\
\hline & 3 & 17.4 & 13.1 to 21.8 & 1.0 \\
\hline & 4 & 6.9 & -0.9 to 14.6 & 1.0 \\
\hline & 5 & 9.7 & 1.3 to 18.2 & 1.0 \\
\hline & 6 & 5.9 & -4.8 to 16.6 & 0.79 \\
\hline & 7 & -7.0 & -17.9 to 3.8 & 1.0 \\
\hline & 8 & 7.7 & 0.3 to 15.1 & 1.0 \\
\hline \multirow{12}{*}{ Month } & December & Referent & & $<0.001$ \\
\hline & January & -6.9 & -12.1 to -1.7 & 0.63 \\
\hline & February & -8.2 & -13.3 to 3.2 & 0.10 \\
\hline & March & -7.8 & -13.0 to -2.6 & 0.22 \\
\hline & April & -8.4 & -13.2 to -3.6 & $<0.05$ \\
\hline & May & -11.7 & -16.3 to -7.1 & $<0.001$ \\
\hline & June & -7.5 & -12.2 to -2.7 & 0.14 \\
\hline & July & -7.4 & -12.0 to -2.9 & 0.10 \\
\hline & August & -6.8 & -11.7 to -1.9 & 0.44 \\
\hline & September & -3.6 & -8.4 to 1.2 & 1.0 \\
\hline & October & -1.7 & -6.5 to 3.1 & 1.0 \\
\hline & November & -3.8 & -8.6 to 1.0 & 1.0 \\
\hline
\end{tabular}

${ }^{1} \mathrm{BB}=$ Belgian Blue; HF $=$ Holstein Friesian; HF $\times \mathrm{BB}=$ crossbreed.

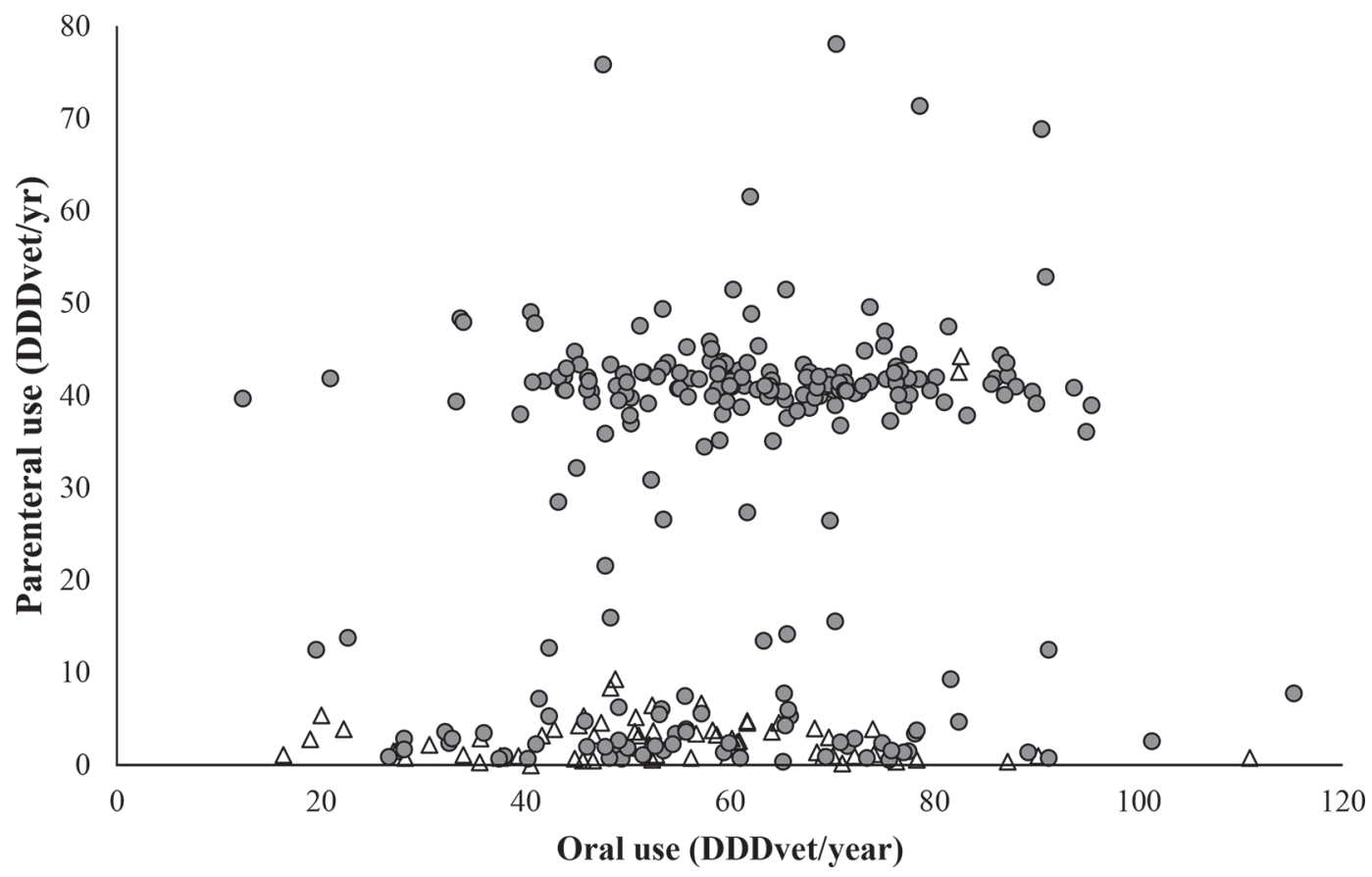

Figure 2. Association between oral and parenteral antimicrobial usage [AMU; defined daily dose animal per year (DDDvet/yr), live weight] of 78 veal farms, 295 production cycles, managed by a single veterinary practice in Flanders, Belgium (2014-2016), explained by the use of longacting macrolides in a production cycle (filled circle). Production cycles where no long-acting macrolides were used (open triangle) are lower in parenteral use. 
February, March, and May. Finally, in September more usage was observed than in February. Breed differences were seen for MacroC $(\mathrm{HF}, \mathrm{HF} \times \mathrm{BB}<\mathrm{BB})$ and $\mathrm{OTC}$ $(\mathrm{HF}, \mathrm{HF} \times \mathrm{BB}>\mathrm{BB})$. Veal company was a risk factor for all antimicrobial classes (AMX: 1, 2, $3>8$; DOX: $2>8$; MacroC: $4>8$; AminoS: $1>4$; TMS: $1<4$ ), except for OTC and FLOR. Herd size is only a risk factor for the use of FLOR, with larger herds using more FLOR. The use of PEN was almost nonexistent and no statistics could be performed.

\section{Mortality Risk and Association with Total AMU and Different Antimicrobial Classes}

Average mortality risk was $2.9 \%$ (SD: $1.3 ; \mathrm{R}: 0-7.1$ ). Higher mortality was seen in beef calves (4.0\%; SD: 1.42; R: $1.3-7.0)$ compared with dairy $(2.7 \%$; SD: 1.34 ; R: $0.0-7.1 ; P=0.04)$ and crossbreeds (2.4\%; SD: 0.8 ; R: $1.2-5.8 ; P=0.09)$. Univariable associated factors with mortality risk were herd size (per 100 calves), year, breed, veal company, CS3/4, COL, MacroLA, MacroC, OTC, AMX, TMS, FLOR, AminoS, and LincosA. The final multivariable model showed increasing herd size, breed, veal company $(1>2$ and $8 ; P<0.001)$, and use of TMS as risk factor for mortality, whereas uses of OTC and AminoS were protecting factors (Table 5). No significant association was observed between mortality risk and total AMU. However, mortality significantly differed between veal companies (Figure 6).

\section{DISCUSSION}

Availability of a huge data set covering over $30 \%$ of the Belgium veal industry using standard definitions in compliance with the Dutch law to quantify and compare AMU was a unique opportunity (DGZ, 2017). We used this information to identify factors that influence AMU in veal calves, which might potentially be of international interest. Total AMU data were calculated based on a SW to allow international comparison. A first key finding was that total AMU for dairy veal calves, 26.4 DDDvet/yr (SW), approached current levels in the Netherlands (25.1 DDDvet/yr), but was much lower than the 55.5 DDDvet/yr over different breeds in France (Jarrige et al., 2017; SDA, 2017). The reported AMU of this veterinary practice (32.3 DDDvet/yr) signifies a voluntary reduction of $46 \%$ compared with the national landmark of 60 DDDvet/yr set in 2007 to 2009 (SW: $164 \mathrm{~kg}$ ) to which this practice also contributed farms (Pardon et al., 2012a). This reduction is similar to what has been achieved in the Netherlands (43.9\%) by legislation (SDA, 2017). The veterinary practice is almost in compliance with the Belgian targets set for 2020 (AMCRA, 2016). The voluntary reduction in this

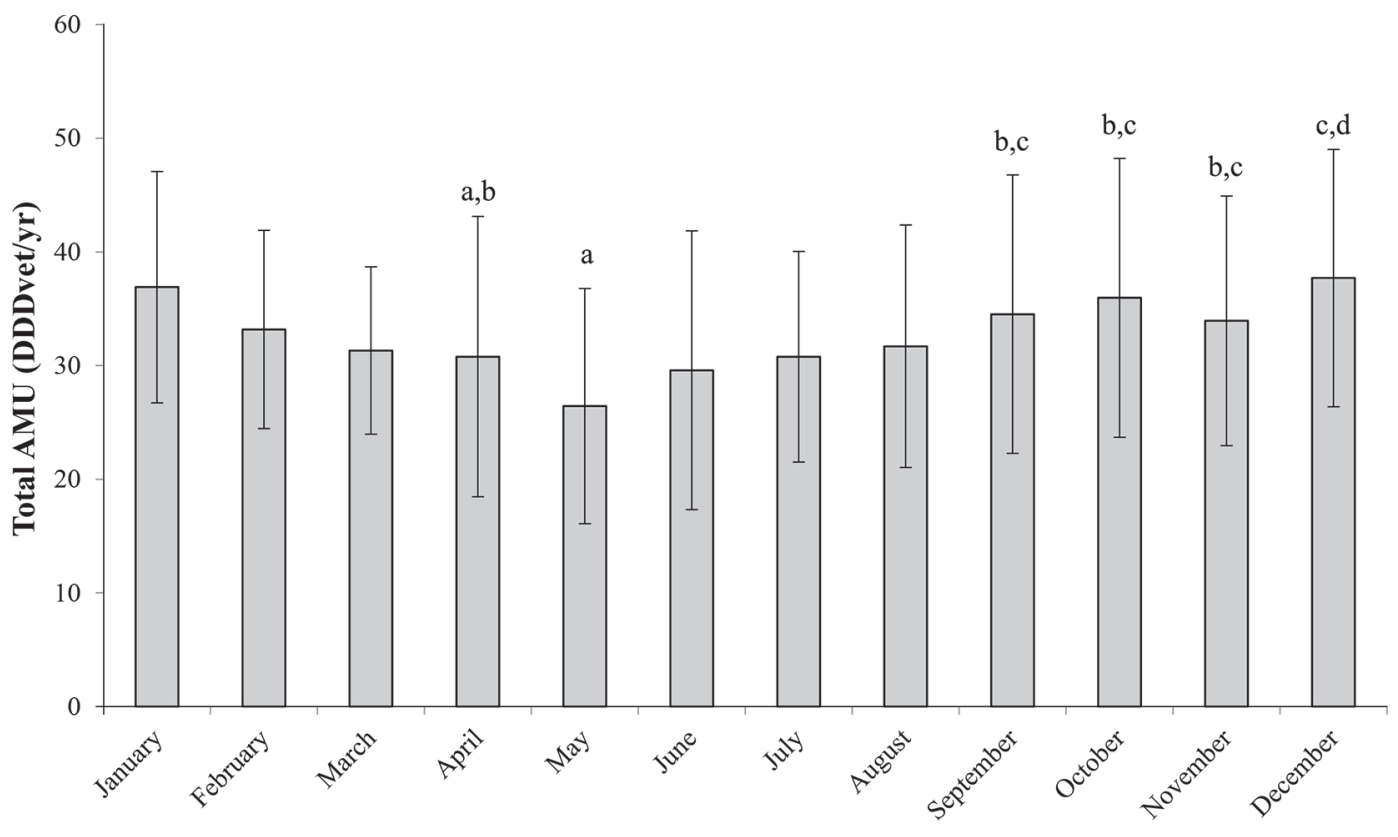

Month of arrival

Figure 3. Distribution of total antimicrobial usage (AMU; defined daily dose animal per year, standard weight) per month of arrival of 78 veal farms, 295 production cycles, managed by a single veterinary practice in Flanders, Belgium (2014-2016). Error bars indicate SD. Different letters $(\mathrm{a}-\mathrm{d})$ indicate a significant difference $(P<0.05)$ in antimicrobial use between months. 


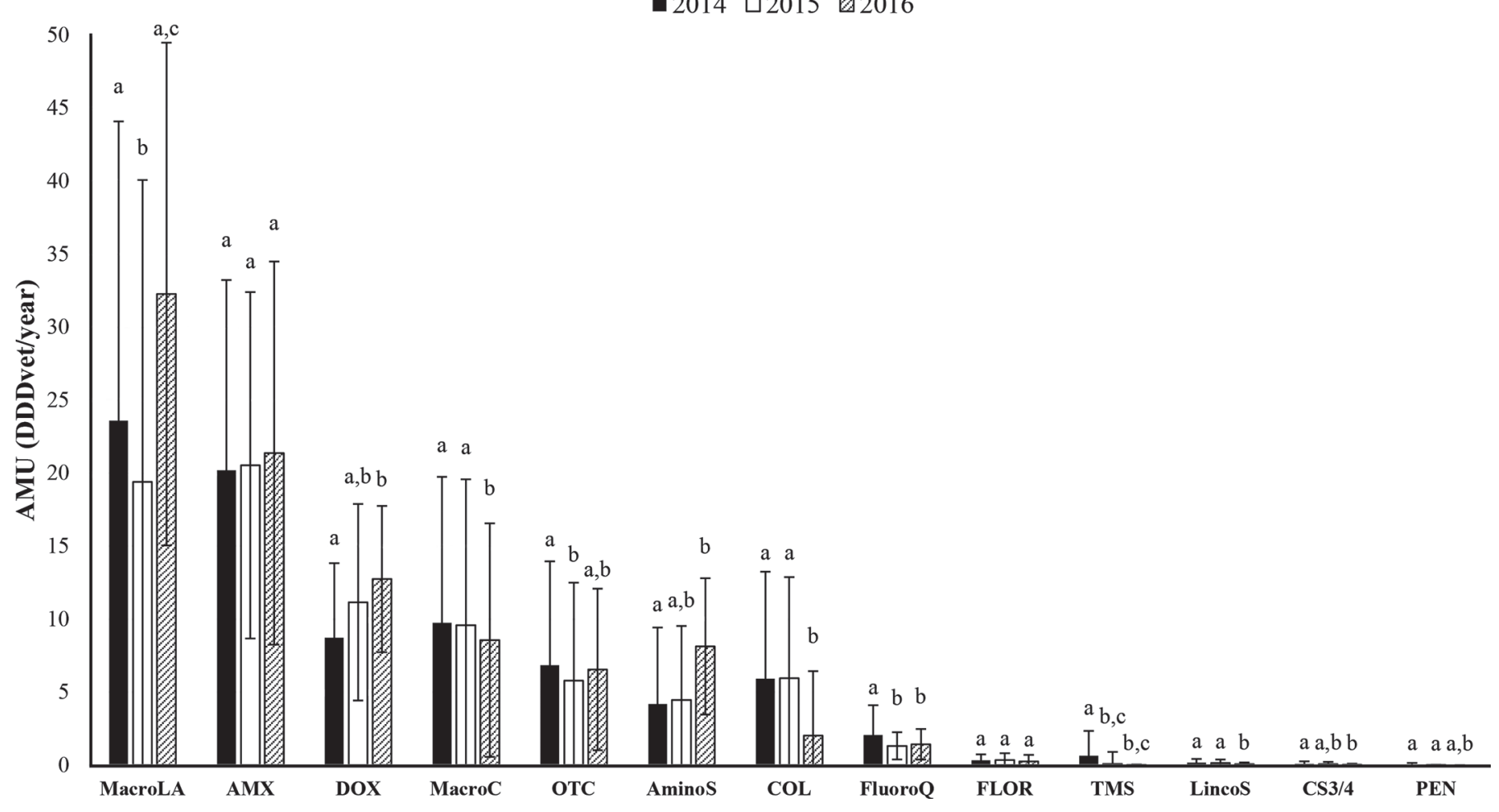

Figure 4. Trends in consumption of different antimicrobial classes of 78 veal farms, 295 production cycles, managed by a single veterinary practice in Flanders, Belgium (2014-2016). MacroLA = long-acting macrolides; AMX = amoxicillin; DOX = doxycycline; MacroC = classic macrolides; OTC $=$ oxytetracycline; AminoS $=$ aminosides; $\mathrm{COL}=$ colistin; FluoroQ $=$ fluoroquinolones; FLOR $=$ florphenicol; TMS $=$ trimethoprim sulfonamides; LincoS = lincosamides; CS3/4 = cephalosporins of third and fourth generation; PEN = penicillin. Antimicrobial usage (AMU) expressed in defined daily dose animal per year based on live weight. Different letters (a-c) within one antimicrobial class indicates significant difference in antimicrobial use between years (2014-2016). Error bars indicate SD.

veterinary practice without legislative pressure could be explained by their proactive nature. Likely they were influenced by the Dutch policy, as they also serve Dutch farms (not included in this study).

As previously observed, respiratory diseases are the main indication for AMU (Pardon et al., 2012a; Fertner et al., 2016; Lava et al., 2016b). Logically, initial empirical treatment was directed toward Mycoplasma bovis, the dominant respiratory pathogen in veal systems (Pardon et al., 2011), which may have reduced the need for retreatment. The effects of national program for bovine viral diarrhea virus, initiated in 2015, on AMU cannot be evaluated based on the current data. Most likely, societal and political pressure together with increased awareness on AMR and responsible AMU were the dominant drivers of this reduction. Parenteral AMU (23.8\%) increased compared with older studies where AMU was almost exclusively administered orally (Pardon et al., 2012a; Lava et al., 2016a). However, this is still in huge contrast to veal calves in Denmark, where $85.4 \%$ of total AMU is given parenterally (Fertner et al., 2016). Both the reduction in total AMU, as increased use of injectable antimicrobials, might have contributed to the observed reduction of AMR in indicator bacteria from veal calves as shown recently in the Belgian monitoring program (Chantziaras et al., 2014; Callens et al., 2018).

A second point is that the use of the critically important FluoroQ and CS3/4 decreased very substantially compared with 2007 to 2009 (96\%) and national targets have already been met (Pardon et al., 2012a; AMCRA, 2016). FluoroQ were still used at almost all farms, but this is not necessarily a negative observation. Their use might be limited to highly critical cases, and therefore absolutely rational for welfare reasons. In contrast, a worrisome observation is that the decrease in oral AMU, FluoroQ, and CS3/4 is compensated by an increased use of especially MacroLA. As they are also classified as critically important for human medicine, their increased use does not appear to be a sustainable solution (WHO, 2011). The high use of macrolides could be explained by their main indication, namely respiratory diseases. The high use of macrolides is unique to this veterinary practice because tetracyclines were the most frequently used antimicrobials in France and the Netherlands (Jarrige et al., 2017; SDA, 2017). This 
Table 4. Summary table ( $P$-values) of risk factor analyses for the use of different antimicrobial compounds based on a data set containing 78 veal farms, 295 production cycles, managed by a single veterinary practice in Flanders, Belgium $(2014-2016)^{1}$

\begin{tabular}{|c|c|c|c|c|c|c|c|}
\hline Item & Model & Year & $\begin{array}{l}\text { Month of } \\
\text { arrival }\end{array}$ & Breed & $\begin{array}{c}\text { Veal } \\
\text { company }\end{array}$ & $\begin{array}{c}\text { Herd size } \\
\text { (per } 100 \text { calves) }\end{array}$ & $\begin{array}{c}\text { Mortality risk } \\
(\%)\end{array}$ \\
\hline \multicolumn{8}{|l|}{ Critically important } \\
\hline Long-acting macrolides & LR & 0.02 & NS & NS & $<0.01$ & NS & NS \\
\hline Colistin & LR & $<0.001$ & NS & 0.05 & $<0.01$ & NS & NS \\
\hline \multicolumn{8}{|l|}{ Mainly oral route } \\
\hline Classic macrolides & MM & $<0.05$ & NS & $<0.001$ & $<0.001$ & NS & NS \\
\hline Oxytetracycline & LR & 0.06 & NS & $<0.01$ & NS & NS & NS \\
\hline Aminosides & LR & $<0.01$ & NS & NS & $<0.001$ & NS & NS \\
\hline Trimethoprim-sulfonamides & LR & $<0.001$ & NS & NS & $<0.01$ & NS & NS \\
\hline \multicolumn{8}{|l|}{ Mainly parenteral route } \\
\hline Florphenicol & $\mathrm{LR}$ & NS & NS & NS & NS & $<0.01$ & NS \\
\hline Lincosamides & LR & 0.1 & NS & NS & 0.02 & NS & NS \\
\hline
\end{tabular}

${ }^{1}$ In case of logistic regression, veal companies were clustered into 4 companies based on size. MM $=$ linear mixed model. LR $=$ logistic regression. NS: $P>0.10$. Due to very low use of penicillin, risk factors could not be determined.

${ }^{2} \log (\mathrm{x}+1)$.

could be explained by personal preference, and stresses the important influence of the prescriber. Increased use of DOX and AminoS could be explained by targeting $M$. bovis and septicemia, respectively. Overall, it was remarkable to see that between 2014 and 2016 no further reduction in AMU was found. It is possible that the veal sector in Belgium has reached the same plateau phase as observed in the Netherlands and motivation to further reduce might no longer be present (SDA, 2017). Also, the decrease of AMR in Escherichia coli from veal calves stagnated (Callens et al., 2018).
Third, the study identified several factors associated with AMU, namely year, season, and breed. Meteorological conditions (abrupt changes in humidity and temperature) and natural variation might be responsible for the slight, but significant increase in AMU between 2015 and 2016. May appears to be the best month to start a veal production cycle in contrast to the winter months. Also, Fertner et al. (2016) found a higher AMU in autumn and winter. This could be due to respiratory infections, because these are most common in autumn and start of winter (Andrews, 1976).

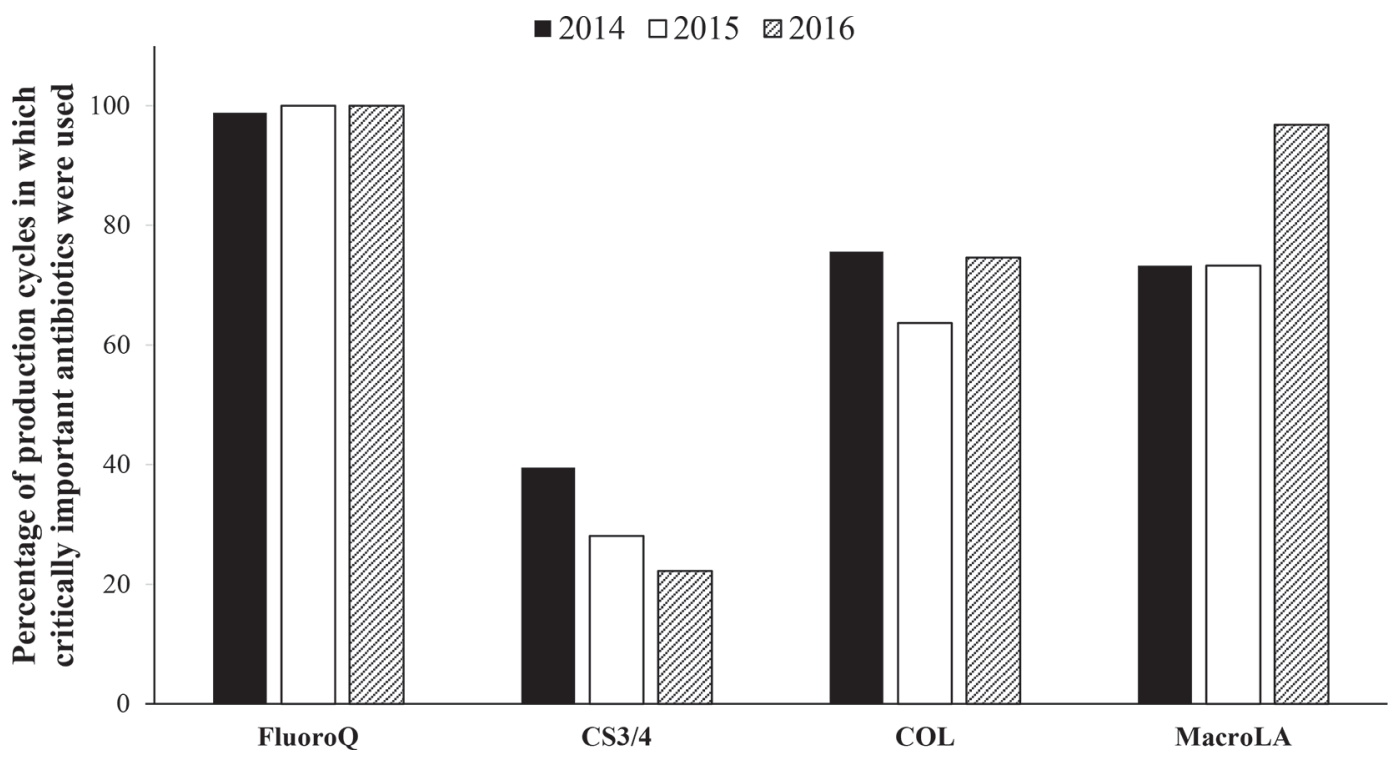

Figure 5. Percentage of critically important antibiotics (FluoroQ $=$ fluoroquinolones; CS3/4 = cephalosporins of the third and fourth generation; COL = colistin; MacroLA = long-acting macrolides) used over 78 veal farms, 295 production cycles, managed by a single veterinary practice in Flanders, Belgium (2014-2016). 
Table 5. Multivariable model relationship between mortality risk (\%) and total antimicrobial usage and different classes based on 78 veal farms, 294 production cycles, managed by a single veterinary practice in Flanders, Belgium (2014-2016)

\begin{tabular}{|c|c|c|c|c|}
\hline Parameter & Category & $\beta$ & $95 \% \mathrm{CI}$ & $P$-value \\
\hline Intercept & & 2.47 & 1.47 to 3.47 & $<0.001$ \\
\hline \multirow[t]{3}{*}{ Breed $^{1}$} & $\mathrm{BB}$ & Referent & & $<0.01$ \\
\hline & $\mathrm{HF}$ & -1.03 & -1.61 to -0.44 & $<0.001$ \\
\hline & $\mathrm{HF} \times \mathrm{BB}$ & -0.59 & -1.08 to -0.10 & 0.12 \\
\hline \multirow[t]{8}{*}{ Veal company } & 8 & Referent & & $<0.001$ \\
\hline & 1 & 2.12 & 1.30 to 2.95 & $<0.001$ \\
\hline & 2 & 0.65 & -0.14 to 1.45 & 1.00 \\
\hline & 3 & 1.28 & 0.08 to 2.48 & 1.00 \\
\hline & 4 & 1.03 & -0.54 to 2.59 & 1.00 \\
\hline & 5 & 0.70 & -1.34 to 2.74 & 1.00 \\
\hline & 6 & 0.64 & -1.35 to 2.64 & 1.00 \\
\hline & 7 & 0.66 & -0.66 to 1.98 & 1.00 \\
\hline Herd size (per 100 calves) & & 0.00 & -0.00 to 0.00 & 0.07 \\
\hline Aminosides & & 0.02 & -0.04 to 0.00 & 0.05 \\
\hline \multirow[t]{2}{*}{ Oxytetracycline } & Use & Referent & & 0.04 \\
\hline & No use & 0.24 & 0.01 to 0.48 & \\
\hline \multirow[t]{2}{*}{ Trimethoprim-sulfonamides } & Use & Referent & & 0.01 \\
\hline & No use & -0.32 & -0.57 to -0.07 & \\
\hline
\end{tabular}

${ }^{1} \mathrm{BB}=$ Belgian Blue; HF $=$ Holstein Friesian; HF $\times \mathrm{BB}=$ crossbreed.

In contrast, in France (Jarrige et al., 2017) no association between month of arrival and AMU was found. However, data were only collected between December and June.

Breed is a risk factor for total AMU as well as for different classes of antimicrobials (COL, OTC, and MacroC). In beef and crossbreeds more antimicrobials were used than in dairy calves. Also in smallholder Swiss veal farms an increased AMU was seen when the portion of beef breeds was higher (Lava et al., 2016b). On the one hand this can be explained by the higher suscepti- bility of beef breeds, in particular $\mathrm{BB}$, for respiratory diseases, arthritis, and hemorrhagic enteritis (Bureau et al., 1999; Pardon et al., 2012b). On the other hand, beef breeds have higher value and an increased mortality risk (as also evidenced again in this study). Likely the risk aversive nature of the owners might tempt veterinarians and farmers to initiate an antimicrobial therapy more easily. Risk aversion has been associated with prophylactic AMU before (Ge et al., 2014). Beef breeds have higher odds to receive MacroC compared with Holsteins and crossbreeds, likely because the main

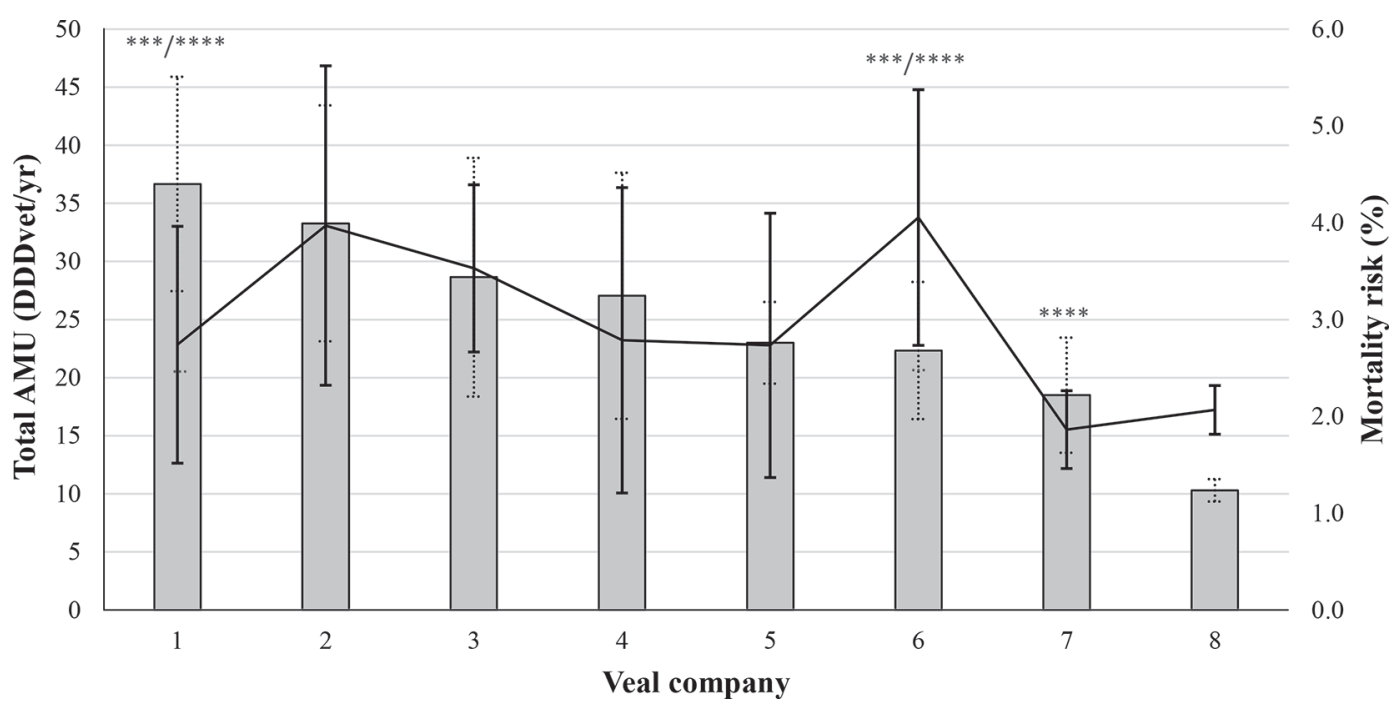

Figure 6. Differences in total antimicrobial use (bar) and mortality risk (\%; line) between white veal companies based on 78 veal farms, 295 production cycles, managed by a single veterinary practice in Flanders, Belgium $(2014-2016)$. *** Significantly $(P<0.001)$ different in total antimicrobial usage (AMU), $* * * *$ significantly $(P<0.001)$ different in mortality risk $(\%)$. Error bars indicate SD. 
indication of these antimicrobials are respiratory diseases. Benchmarking is a part of monitoring programs of independent and governmental organizations outside Belgium and has been proven effective (SDA, 2017). With breed being a risk factor for AMU, the authors opt to initiate breed-adjusted benchmarking for veal calves in Belgium. In contrast to previous studies, herd size did not remain a significant risk factor for total AMU in the multivariable model. In Denmark, the number of calves introduced was positively associated with total AMU (Fertner et al., 2016) as was the case in Switzerland with metaphylactic AMU (Lava et al., 2016a). The possible association of herd size with AMU is difficult to analyze because of intervening variables such as purchase, herds of origin, infection pressure, management, and biosecurity (Bokma et al., 2018).

In the authors' opinion, the finding with potentially the most implications for practice is that when working with the same veterinary practice, the veal company remained a significant risk factor for total AMU, different classes of antimicrobials, and especially for the use of critically important antimicrobials. Previous work on veal calves in France showed that the association between veterinarian and total AMU was stronger than between veal company and total AMU (Jarrige et al., 2017). In this study, veterinarians were highly associated with veal companies, making it more difficult to estimate the effect of the veal company. In the authors' opinion, the findings in the present study show that the veal company should be a separate target for sensitization campaigns. Extrapolation of this observation to other countries needs to be done with care because relationships and organizational culture between farmers, veal companies, and veterinarians might heavily differ between countries. Nevertheless, identification of key influencers of AMU in each system is essential to achieve a rapid and sustainable reduction in AMU.

The mean mortality risk of $2.9 \%$ for dairy calves as observed in this study is the lowest mortality reported for dairy veal calves so far [e.g., Belgium 2009-2010 (4.9\%; Pardon et al., 2012b), Switzerland 2013 (3.6\%; Lava et al., 2016a), and Canada 2016 (7.0\%; Renaud et al., 2018)]. Even in the more sensitive BB breeds, a very low mortality risk (4.0\%) could be reached despite that animals already enter the farms at an age of $2 \mathrm{wk}$ old. No association between mortality risk and total AMU was found. A positive association between AMU and mortality risk higher than $5 \%$ in veal calves was found in France (Jarrige et al., 2017) and between individual AMU and mortality risk in Switzerland (Bähler et al., 2012). This positive association can most likely be explained by the reaction of the farmer to use antimicrobials more rapidly and frequent when confronted with high mortality. In contrast, higher AMU is a pro- tective factor for mortality when all calves in the cohort were treated (Bähler et al., 2012). No association was observed between month of arrival and mortality, which can justify the increased use of total AMU in some months to prevent animal suffering. However, a relationship was observed between different antimicrobial classes and total mortality. Use of TMS was a risk factor for mortality, whereas the use of OTC and increased use of AS were protective. Most likely this is explained by the fact that TMS is not effective against $M$. bovis, resulting in therapy failure and the need for a new therapy. In contrast, OTC is effective against mycoplasmata. The AminoS are important molecules to prevent mortality when septicemia occurs, hence the increased use when confronted with rapidly spreading septicemic conditions such as salmonellosis or histophilosis.

This study was subject to some limitations, which are mentioned here. Selection bias occurred as all farms belonged to a single practice and therefore observations from this study might not be representative for the whole of the Belgian industry. An advantage of this data set compared with previous studies is that all farms were served by the same veterinary practice, but belonged to different veal companies. Treatment by other veterinarians could be excluded because of solid relationships between veterinary practice, veal company, and farmer. Of all white veal herds available, only $5.1 \%(16 / 311)$ were excluded from the study, mainly because of software issues. These farms belonged mainly to 4 very small veal companies. Overall, further selection bias within the herds of this practice is believed to be limited. Misclassification bias is believed to be limited as AMU was linked to the official pharmacy documents of the practice. In contrast to total AMU, for the separate antimicrobial classes data were only available based on LW. This resulted in a better estimate, but usage of a specific class cannot be compared with the national Dutch system.

\section{CONCLUSIONS}

The present study showed that current AMU in the largest Belgian veal veterinary practice is in line with the contemporary levels in the Netherlands and almost halved compared with the Belgian landmark of 2007-2009. The use of critically important antibiotics (FluoroQ, CS3/4) has massively decreased, but FluoroQ use appears still necessary on many farms. The stagnating reduction over 2014-2016 is concerning, as is the shift toward the increased use of MacroLA. The need for breed-specific benchmarks in veal calves was illustrated and the influence of month of arrival shown, suggesting the use of specific preventive measures in autumn and winter time. In this study no increased 
mortality with decreasing AMU as a sign of compromised animal welfare could be evidenced at the current levels of AMU. This suggests that further reduction should be stimulated and that the veal company can have an important influence to achieve this.

\section{ACKNOWLEDGMENTS}

We acknowledge the whole team of the veterinary practice for their consistent record keeping and the farmers and integrators for participating. Data for this study were collected as part of a master in veterinary medicine thesis in 2017, conducted at Ghent University. Jade Bokma is supported by a grant of the Belgian Federal Public Service, Health, Food Chain Safety and Environment (RF 17/6313 MALDIRESP).

\section{REFERENCES}

Agunos, A., D. F. Léger, C. A. Carson, S. P. Gow, A. Bosman, R. J. Irwin, and R. J. Reid-Smith. 2017. Antimicrobial use surveillance in broiler chicken flocks in Canada, 2013-2015. PLoS One 12:e0179384. https://doi.org/10.1371/journal.pone.0179384.

AMCRA. 2016. Convenant tussen de Federale Overheid en alle betrokken sectorpartners betreffende de vermindering van het gebruik van antibiotica in de dierlijke sector. Accessed Apr. 30, 2018. https://www.amcra.be/swfiles/files/NL_FR\%20convenant\%20AB \%2020160630_9.pdf.

Andrews, A. H. 1976. Factors affecting the incidence of pneumonia in growing bulls. Vet. Rec. 98:146-149.

Autoriteit Diergeneesmiddelen (SDA). 2017. Het gebruik van antibiotica bij landbouwhuisdieren in 2016. Trends, benchmarken bedrijven en dierenartsen. Accessed Feb. 23, 2018. https://cdn.i-pulse .nl/autoriteitdiergeneesmiddelen/userfiles/sda\%20jaarrapporten \%20ab-gebruik/sda-rapport-2017.pdf.

Bähler, C., A. Steiner, A. Luginbühl, A. Ewy, H. Posthaus, D. Strabel, T. Kaufmann, and G. Regula. 2012. Risk factors for death and unwanted early slaughter in Swiss veal calves kept at a specific animal welfare standard. Res. Vet. Sci. 92:162-168. https://doi .org/10.1016/j.rvsc.2010.10.009.

Bengtsson, B., and C. Greko. 2014. Antibiotic resistance-consequences for animal health, welfare, and food production. Ups. J. Med. Sci. 119:96-102. https://doi.org/10.3109/03009734.2014.901445.

Bokma, J., J. Dewulf, P. Deprez, and B. Pardon. 2018. Risk factors for antimicrobial use in food-producing animals: Disease prevention and socio-economic factors as the main drivers? Vlaams Diergeneeskd. Tijdschr. 87:186-198.

Bureau, F., C. H. Uystepruyst, J. Coghe, M. Van de weerdt, and P. Lekeux. 1999. Spirometric variables recorded after lobeline administration in healthy Friesian and Belgian white and blue calves: Normal values and effects of somatic growth. Vet. J. 157:302-308.

Callens, B., S. Sarrazin, M. Cargnel, S. Welby, J. Dewulf, B. Hoet, K. Vermeersch, and P. Wattiau. 2018. Associations between a decreased veterinary antimicrobial use and resistance in commensal Escherichia coli from Belgian livestock species (2011-2015). Prev. Vet. Med. https://doi.org/10.1016/j.prevetmed.2017.10.013.

Chantziaras, I., F. Boyen, B. Callens, and J. Dewulf. 2014. Correlation between veterinary antimicrobial use and antimicrobial resistance in food-producing animals: A report on seven countries. J. Antimicrob. Chemother. 69:827-834. https://doi.org/10.1093/jac/ dkt443.
Dierengezondheidszorg Vlaanderen (DGZ). 2017. Jaarverslag Dierengezondheidszorg Vlaanderen, 2016. Accessed Apr. 27, 2018. https://www.dgz.be/sites/default/files/Jaarverslag_2016_DGZ .pdf.

EMA/EFSA. 2016. EMA and EFSA Joint Scientific Opinion on measures to reduce the need to use antimicrobial agents in animal husbandry in the European Union, and the resulting impacts on food safety (RONAFA). Accessed Apr. 30, 2018. https://www.ema .europa.eu/documents/report/ema-efsa-joint-scientific-opinion -measures-reduce-need-use-antimicrobial-agents-animal-husbandry en.pdf.

Fertner, M., N. Toft, H. L. Martin, and A. Boklund. 2016. A registerbased study of the antimicrobial usage in Danish veal calves and young bulls. Prev. Vet. Med. 131:41-47. https://doi.org/10.1016/j .prevetmed.2016.07.004.

Ge, L., M. A. P. M. van Asseldonk, N. I. Valeeva, W. H. G. J. Hennen, and R. H. M. Bergevoet. 2014. A Bayesian belief network to infer incentive mechanisms to reduce antibiotic use in livestock production. NJAS Wagening. J. Life Sci. 70-71:1-8. https://doi.org/10 .1016/j.njas.2014.01.001.

Jarrige, N., G. Cazeau, E. Morignat, M. Chanteperdrix, and E. Gay. 2017. Quantitative and qualitative analysis of antimicrobial usage in white veal calves in France. Prev. Vet. Med. 144:158-166. https: //doi.org/10.1016/j.prevetmed.2017.05.018.

Kamerbrief. 2016. Kamerbrief over vervolgbeleid antibiotica in de veehouderij. Accessed May 1, 2018. https://www.rijksoverheid .nl/documenten/kamerstukken/2016/07/08/kamerbrief-over -vervolgbeleid-antibiotica-in-de-veehouderij.

Lava, M., B. Pardon, G. Schüpbach-Regula, K. Keckeis, P. Deprez, A. Steiner, and M. Meylan. 2016a. Effect of calf purchase and other herd-level risk factors on mortality, unwanted early slaughter, and use of antimicrobial group treatments in Swiss veal calf operations. Prev. Vet. Med. 126:81-88. https://doi.org/10.1016/j .prevetmed.2016.01.020.

Lava, M., G. Schupbach-Regula, A. Steiner, and M. Meylan. 2016b. Antimicrobial drug use and risk factors associated with treatment incidence and mortality in Swiss veal calves reared under improved welfare conditions. Prev. Vet. Med. 126:121-130. https://doi.org/ 10.1016/j.prevetmed.2016.02.002.

Pardon, B., B. Catry, R. Boone, H. Theys, K. De Bleecker, J. Dewulf, and P. Deprez. 2014. Characteristics and challenges of the modern Belgian veal. Vlaams Diergeneeskd. Tijdschr. 83:155-163.

Pardon, B., B. Catry, J. Dewulf, D. Persoons, M. Hostens, K. De Bleecker, and P. Deprez. 2012a. Prospective study on quantitative and qualitative antimicrobial and anti-inflammatory drug use in white veal calves. J. Antimicrob. Chemother. 67:1027-1038. https: //doi.org/10.1093/jac/dkr570.

Pardon, B., K. De Bleecker, J. Dewulf, J. Callens, F. Boyen, B. Catry, and P. Deprez. 2011. Prevalence of respiratory pathogens in diseased, non-vaccinated, routinely medicated veal calves. Vet. Rec. 136:278. https://doi.org/10.1136/vr.d4406.

Pardon, B., K. De Bleecker, M. Hostens, J. Callens, J. Dewulf, and P. Deprez. 2012b. Longitudinal study on morbidity and mortality in white veal calves in Belgium. BMC Vet. Res. 8:26. https://doi.org/ 10.1186/1746-6148-8-26.

Renaud, D. L., T. F. Duffield, S. J. LeBlanc, S. Ferguson, D. B. Haley, and D. F. Kelton. 2018. Risk factors associated with mortality at a milk-fed veal calf facility: A prospective cohort study. J. Dairy Sci. 101:2659-2668. https://doi.org/10.3168/jds.2017-13581.

Timmerman, T., J. Dewulf, B. Catry, B. Feyen, G. Opsomer, A. de Kruif, and D. Maes. 2006. Quantification and evaluation of antimicrobial drug use in group treatments for fattening pigs in Belgium. Prev. Vet. Med. 74:251-263. https://doi.org/10.1016/j.prevetmed .2005.10.003.

WHO. 2011. Critically important antimicrobials for human medicine. 3rd rev. 2011. Accessed Apr. 28, 2018. http://apps.who.int/iris/ bitstream/10665/77376/1/9789241504485_eng.pdf. 